\section{Caliber Persistent Artery in the Upper Lip: A Case Report with Unusual Histopathological Findings}

\author{
Carla Samily de Oliveira Costa ${ }^{1}{ }^{\mathbb{C}}$, Larissa Santos Amaral Rolim ${ }^{1}{ }^{1}$, Rodrigo \\ Porpino Mafra ${ }^{1}{ }^{(\mathbb{D}}$, Lélia Batista de Souza ${ }^{1}$, Leão Pereira Pinto ${ }^{1}$ (D)
}

\begin{abstract}
Caliber persistent labial artery (CPLA) consists in a dilated portion of the main branch of the labial artery without loss of size. The aim of this study is to report a case of a patient diagnosed with CPLA in the upper lip, emphasizing unusual histopathological and immunohistochemical findings. A 67-year-old female patient with complaint of a pulsating upper lip lesion without painful symptomatology. Under a clinical diagnosis of CPLA, and considering that the patient was edentulous and used a total prosthesis, an excisional biopsy of the lesion was performed to avoid future traumas in the region and consequently possible exuberant local bleeding. At anatomopathological examination structures suggestive of lymphoid follicles and germinal centers were visualized. Immunohistochemistry showed positivity for CD20, CD68, desmin and CD34 and negativity for CD4. The patient did not have a history of allergies, cardiovascular, rheumatic or systemic diseases that could justified the findings. The case presents unusual histopathological structures, evidencing the necessity of more studies about this pathology so scarce in the literature.
\end{abstract}

'Department of Dentistry, UFRN Universidade Federal do Rio Grande do Norte, Natal, RN, Brazil

Correspondence: Carla Samily de Oliveira Costa, Av. Sen. Salgado Filho, 1787, Lagoa Nova, 59056-000 Natal, RN, Brasil. Tel: +55-84-3215-4138. e-mail: carlasamily@hotmail.com

Key Words: arteries, lip, immunohistochemistry.

\section{Introduction}

Caliber persistent labial artery (CPLA) consists in a dilated portion of the main branch of the labial artery that penetrates the submucosal tissue without loss of caliber $(1,2)$. Howell and Freeman (3) initially named the condition in 1973 as a "prominent inferior labial artery". Subsequently, Miko et al. (4) renamed it as a "caliber" persistent labial artery, as it is known today. The caliber persistent labial artery has also been described in gastrointestinal tract sites, such as the stomach and jejunum (1). However, this condition is more common in the lower (about 80\% of lesions) and upper lips, and may also appear on the palate $(2,5-7)$.

CPLA does not have a predilection for sex and is found mainly in the elderly population, between 40 and 88 years old, with a mean age of 58 years $(2,7)$. This suggests that its development may be due to an age-related degenerative phenomenon in which collapse of the tonus of the surrounding tissue supporting the artery occurs (2). Moreover, as the patient ages, atherosclerotic vessel alterations may also be a triggering factor for the pulsatile characteristic of this lesion (2). In younger people, it seems to be related to accidental or chronic injury resulting from the pressure imposed by the pulsatile artery at the superficial level, or due to medication, actinic cheilitis and/ or atherosclerosis (7).

In order to diagnose CPLA, clinical diagnosis and imaging criteria and histopathological verification are required
(7). Color Doppler ultrasonography is frequently used for diagnosis, interventional monitoring and monitoring of intracranial and extracranial vascular malformations, among other vascular head and neck abnormalities (8).

In most cases, no treatment is required for CPLA, but if the frequent trauma causes sensitivity or increased volume, treatment is indicated. Conservative methods are usually the first choice, and the surgical approach is recommended only when the aesthetic impact is very important to the patient or when other difficulties apply (7).

In this context, the aim of this study is to present the case report of a patient diagnosed with a caliber persistent artery in the upper lip reporting unusual histopathological and immunohistochemical findings for the first time. In addition, a literature review on CPLA is also presented.

\section{Case Report}

A 67-year-old female patient was referred to a Dental Specialty Center for investigation of a pulsating upper lip lesion without painful symptomatology, with a nodular aspect, measuring about $1.5 \mathrm{~cm}$ in length, implanted in the submucosa, with a firm consistency and reddish color. The patient presented no history of allergies, cardiovascular, rheumatic or systemic diseases. Under a clinical diagnosis of CPLA, and considering that the patient was edentulous and used a total prosthesis, an excisional biopsy of the lesion was performed, in order to avoid future traumas in the region and consequently possible exuberant local bleeding. 
During the surgical procedure, divulsion of adjacent soft tissues and the ligament at the two artery extremities was performed, in order to avoid intense intraoperative hemorrhage (Fig. 1).

A thick artery with stenotic light was presented at the anatomopathological examination, where the layers of the tunica intima, medium and adventitia were observed, with anatomical preservation of all structures, in addition to the presence of vasa vasorum composed of several capillaries sometimes congested by red blood cells and surrounded by a mild inflammatory infiltrate composed of lymphocytes and mast cells (Fig. 2). An intense hemorrhagic extravasation was observed in the periphery of the adventitial layer of the artery, as well as structures suggestive of primary and secondary lymphoid follicles with formations suggestive of germinal centers (Fig. 3).

Due to the presence of unusual histological findings, immunohistochemical stainings were performed for CD20, CD68 and CD4 to confirm exclusively lymphocytic components in structures suggestive of lymphoid follicles. Strong and diffuse immunopositivity was observed for CD20 and CD68 and no immunolabeling was noted for CD4 (Fig. 4). In addition, immunohistochemical labeling for desmin and CD34 were also performed, with immunopositivity observed for the latter. Histochemical Verhoeff staining marked the elastic fibers of the vessel (Fig. 5).

\section{Discussion}

CPLA pathogenesis is still not fully understood. It has been suggested that the development of this abnormality in the lower lip is due to the great caliber of the inferior alveolar artery $(4,6)$. In this condition, the artery walls display increased calibers, which continue to widen even after crossing the mental foramen, passing the orbicularis muscle of the mouth to supply the mucosal region of the lower lip, resulting in CPLA. Although the lower lip is the

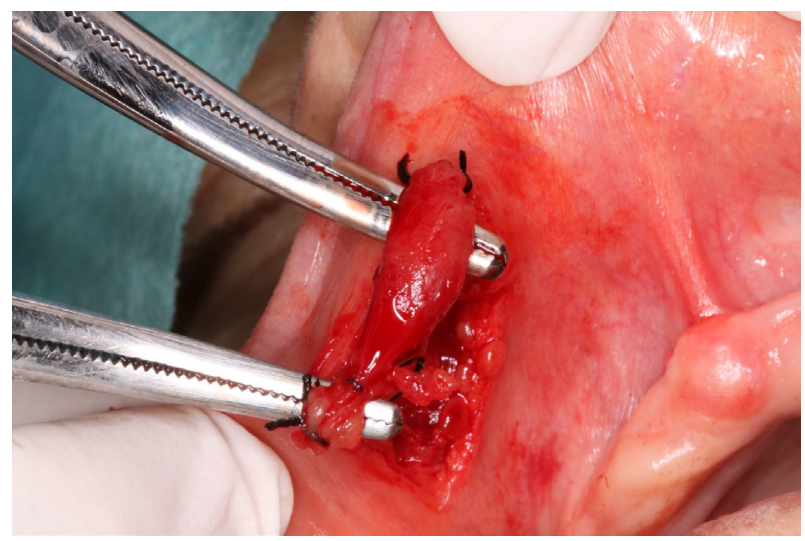

Figure 1. Transoperative showing soft tissue divulsion with artery extremities ligation. most commonly affected, this type of lesion is also found in the upper lip $(5,6)$. Anatomic variations or congenital derivations may supposedly lead to CPLA (5). Since most of these lesions occur in the lower lip, it could be assumed that this condition would be linked to trauma in the region. Another possible cause would be that this lesion represents a change due to aging and that intense sun exposure combined with senile tissue atrophy would result in vascular ectasia $(4,9)$.

The most affected age group is between 40 and 88 years old, and CPLA incidence is reported as occurring in approximately $3 \%$ of the population. Awni and Conn (2) reported five cases in which all CPLA presented on the lower lip. Santagata et al. (10) and Agha-Hosseini and Sheykhbahaei (7), on the other hand, reported upper lip CPLA cases, as described herein.

Currently, in addition to clinical criteria, imaging resources
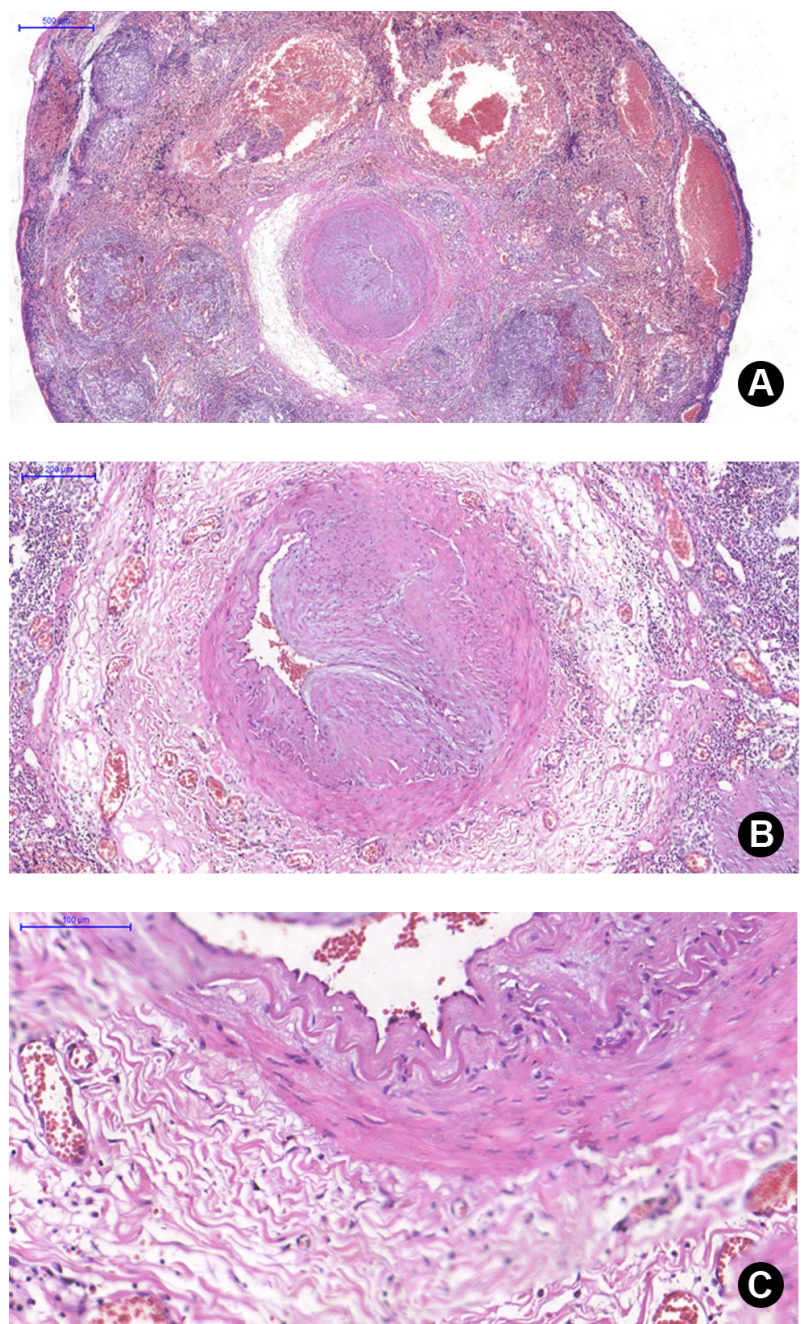

Figure 2. A: CPLA cross section showing prominent muscular layer with extensive red blood cells extravasation and lymphoid tissue in the periphery. B: Artery with stenotic lumen. C: Tunica intima, media, adventitia and vasa vasorum with preserved structures. 
can also be used to diagnose this pathological alteration (7). In specific cases, color Doppler ultrasonography, as a non-invasive and useful tool for preoperative diagnosis and evaluation, as well as in the follow-up of lesions, eliminates the need for surgical interventions for diagnosis of typical pulsatile nodules. In addition, ultrasound can help distinguish this lesion from other vascular lesions of the lip, such as an aneurysm. It is important to emphasize that atypical or chronic cases and persistent ulcerations should be biopsied to elucidate the existence of possible malignant events. $(8,11)$.

Histologically, CPLA lesions are characterized by a normal muscular artery with irregular light and unusual size for a submucosal location (1). Vascular alteration fragments were observed during the histopathological examination of the present case, with a thick artery presenting stenotic light, where it was possible to observe the tunica intima layers (coated by endothelial cells and supported by loose subendothelial connective tissue), the internal elastic limit (formed by elastic fibers), the middle tunica (formed by concentric layers of smooth muscle cells) and, more externally, the adventitial tunica composed of loosely arranged collagen fibers. The vasa vasorum comprised several capillaries, sometimes congested by red blood cells. An intense hemorrhagic extravasation was noted in the periphery of the adventitial layer of the artery, in addition to structures suggesting primary and secondary lymphoid follicles, with formations similar to germinal centers.
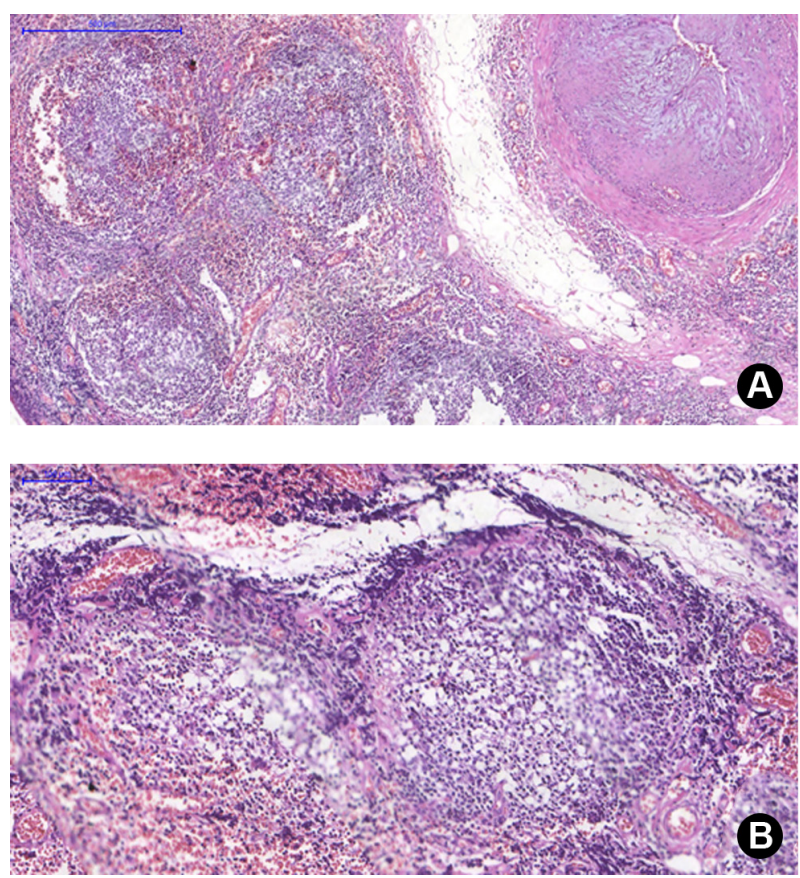

Figure 3. A: Presence of lymphoid follicles at vessel periphery. B: Two lymphoid aggregates resembling secondary lymphoid follicles, with dark and light areas present in germinal centers

Due to the presence of these structures, immunohistochemical analyses were performed to better evidence the nature of these unusual findings. CD34 labeling was performed, similar to what was carried out by Santagata et al. (10) and Khalele et al. (12), and tested positive. In the case described by Khalele et al. (12), the patient was diabetic and histological findings indicated that the artery was surrounded by an inconspicuous inflammatory infiltrate, whereas in the present case, lymphoid tissue was strongly positive for $\mathrm{CD} 20$, diffuse CD68 and negative for CD4, which characterizes a lymphoid tissue composed exclusively of B lymphocytes, with sparse macrophages inside, organized in the same form and structure as a secondary lymphoid organ with a germinal center formation.

Primary lymphoid organs comprise the bone marrow and thymus and are primarily responsible for the selection of virgin $B$ and $T$ lymphocytes with highly diversified $B$ and $T$ cell receptors in their germ sequences. Secondary lymphoid
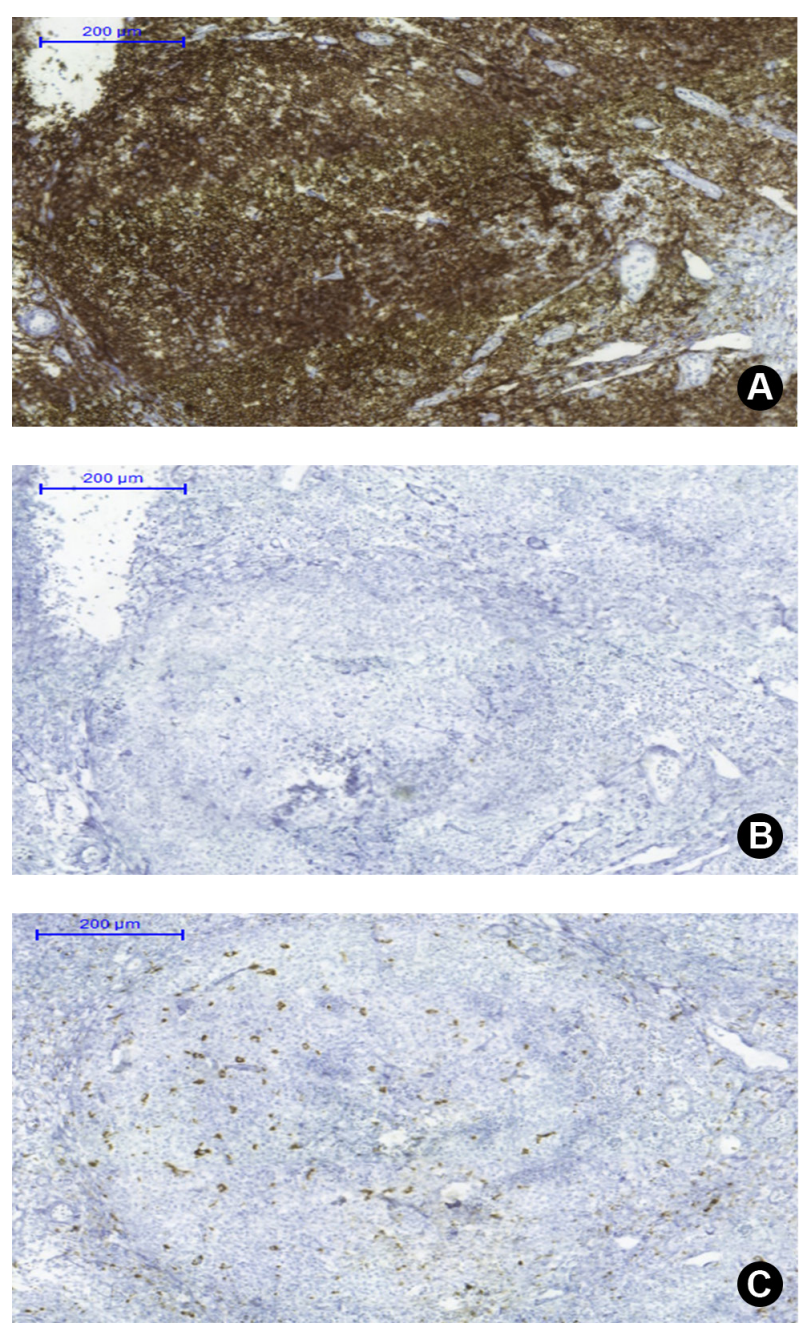

Figure 4. Immunohistochemical labeling for A: CD20, B: CD4 and C: CD68 on the same lymphoid follicle. 
organs, such as lymph nodes, spleen and mucosal associated lymphoid tissues (MALT) regulate leukocyte recirculation and are critical for the assembly of high specificity in adaptive immune responses following antigen challenge. Tertiary lymphoid organs are defined as clusters of lymphomonocytic cells that form in chronic inflammation sites in peripheral non-lymphoid organs. Because of this, they are also known as ectopic lymphoid structures (ELEs), and acquire phenotypic features characteristic of secondary lymphoid organs (13-15). Thus, we can assume that these structures similar to lymphoid follicles with germinative center formations could, in fact, be treated as ELEs in the periphery of the vessel, since the possibility of these structures being MALT was ruled out, since there was no mucosal tissue associated with the biopsy fragment due to adjacent tissue divulsion during surgery.

Aloisi and Pujol-Borrell (16) observed the presence of organized lymphoid structures resembling secondary
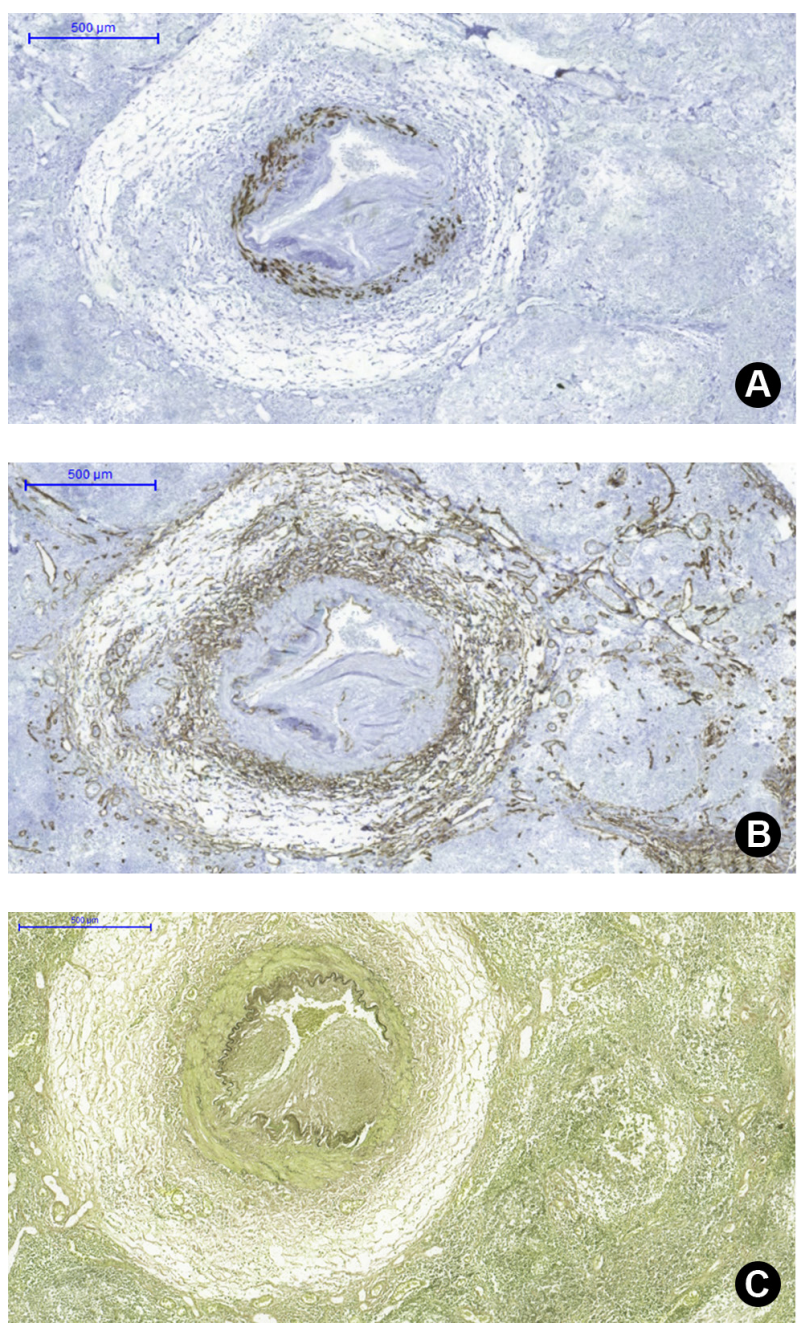

Figure 5. Immunohistochemical labeling for A: desmin and B: CD34. C: Histochemical labeling for Verhoeff, evidencing elastic fibers present between tunica media and adventitia. lymphoid organs in tissues that are the target of chronic inflammatory processes, such as autoimmunity and infection, indicating that lymphoid neogenesis may play a role in the maintenance of immune responses against persistent antigens. According to Van de Pavert et al. (15), ELEs develop more frequently in target organs that are sites of chronic antigen-directed inflammation, which can be found in patients presenting rheumatoid arthritis and in the salivary glands of patients with Sjögren's syndrome. However, the patient in our case reported having no knowledge of any systemic disease of immunological origin during the anamnesis, present in other patients with ELEs. It may be supposed that there would be some ongoing condition not yet investigated in the patient that would justify the presence of these structures. However, the findings reported herein still remain of indefinite etiology.

Although some reports of caliber persistent arteries in the stomach are available, among other gastrointestinal tract areas, with some cases presenting a history of hemorrhage, and even death of the patient, no reports of bleeding related to this lip injury exist. However, severe blood loss is possible after traumatic occurrence, even with specimen excision for biopsy, the risk of which is imminent if the surgeon does not have the proper training for the procedure to be performed in the artery (3).

According to Awni et al. (2), bleeding was not a significant factor during CPLA treatment, occurring in only two of five cited cases. Local hemostasis measurements were used to control bleeding and no subsequent patient complaints in this regard were noted, indicating that CPLAs are amenable to surgery without serious complications, during or after the surgical procedure.

Despite the existence of few literature reports, CPLA can be found in the oral cavity. The clinical CPLA case presented herein indicates histopathological structures that deviate from normal and, thus, led to discussions on the histochemical and immunohistochemical findings regarding the pathogenesis of this disease. Indeed, CPLA pathogenesis is not adequately clarified in literature reports and, until patient clinical examination and follow-up, no systemic patient alterations were indicated that could establish cause/effect as an element for the characterization of CPLA etiopathogenesis.

\section{Resumo}

Artéria labial de calibre persistente (ALCP) consiste em uma parte dilatada do ramo principal da artéria labial que penetra no tecido submucoso sem perda de calibre. 0 objetivo desse estudo é relatar um caso de uma paciente diagnosticada com ALCP em lábio superior, enfatizando os achados histopatológicos e imuno-histoquímicos incomuns. Paciente de 67 anos, sexo feminino, com queixa de lesão em lábio superior, pulsante, sem sintomatologia dolorosa. Diante do diagnóstico clinico de $A L C P$, e considerando que a paciente era edêntula e usuária de prótese total, foi realizada biópsia excisional para evitar futuros traumas na 
região e, consequentemente, sangramento local exuberante. Ao exame anatomopatológico foram visualizadas estruturas sugestivas de folículos linfoides e com formações sugestivas de centros germinativos. No exame imuno-histoquimico observou-se imunopositividade para CD20, CD68, desmina e CD34 e sem imunomarcação para CD4. A paciente relatou não possuir histórico de alergias, doenças cardiovasculares, reumáticas ou sistêmicas que justificassem os achados. 0 caso apresenta estruturas histopatológicas incomuns, corroborando a necessidade de mais estudos acerca dessa lesão tão pouco discutida na literatura.

\section{Acknowledgements}

This study was granted in part by the funding agency Coordenação de Aperfeiçoamento de Pessoal de Nivel Superior (CAPES), Brazil; Finance Code 001.

\section{References}

1. Costa SAP, Ruiz MM, Kaba SP, Florezi GP, Lemos Júnior AS, Witzel AL. Caliber-persistent artery. Case rep dent 2015;1-5.

2. Awni S, Conn B. Caliber-Persistent Labial Artery: A rarely recognized cause of a lower lip swelling-report of 5 cases and review of the literature. J Oral Maxillofac Surg 2016;74:1391-1395.

3. Howell $J B$, Freeman RG. The potential peril from caliber-persistent arteries of the lips. J Am Acad Dermatol 2002;46:256-259.

4. Miko T, Adler P, Endes P. Simulated cancer of the lower lip attributed to a "caliber persistent" artery. J Oral Pathol 1980;9:137-144.

5. Lovas JG, Rodu B, Hammond HL, Allen CM, Wysocki GP. Caliberpersistent labial artery: A common vascular anomaly. Oral Surg Oral Med Oral Pathol Oral Radiol Endod 1998;86:308-312.

6. Wong, KK, Roberts F, Cauchi P, Diaper C. Caliber persistent artery of the eyelid. Graefes Arch Clin Exp Ophthalmol 2011:249:1395-1397.

7. Agha-Hosseini F, Sheykhbahaei N. A new approach to the management of caliber-persistent artery: A case report and analysis of previously reported cases. Int J Dermatol 2016;55:11-16.

8. Vazquez L, Lombardi T, Guinand-Mkinsi H, Samson J. Ultrasonography: A noninvasive tool to diagnose a caliber-persistent labial artery, an enlarged artery of the lip. J Ultrasound Med 2005;24:1295-1301.

9. Marshall RJ, Leppard, BJ. Ulceration of the lip associated with a 'calibrepersistent artery'. Br J Dermatol 1985;113:757-760.

10. Santagata $M$, Maglione $M$, Colella G, D'Amato S. Calibre persistent labial artery: Clinical features and immunohistochemistry diagnosis. J Maxillofac Oral Surg 2015;14:845-847.

11. Wortsman $X$, Calderón $P$, Arellano J, Orellana Y. High-resolution color Doppler ultrasound of a caliber-persistent artery of the lip, a simulator variant of dermatologic disease: case report and sonographic findings. Int J Dermatol 2009;48:830-833.

12. Khalele BAEO. Palatal caliber persistent artery in a diabetic patient. Fut Dent J 2016;2:99-101.

13. Bombardieri $\mathrm{M}$, Lewis $\mathrm{M}$, Pitzalis, $\mathrm{C}$. Ectopic lymphoid neogenesis in rheumatic autoimmune diseases. Nat Rev Rheumatol 2017;13:141154.

14. Drayton DL, Liao S, Mounzer RH, Ruddle NH Lymphoid organ development: from ontogeny to neogenesis. Nat Immunol 2006;7:344353.

15. Van de Pavert, SA, Mebius RE. New insights int the development of lymphoid tissues. Nat Rev Immunol 2010;10:664-674.

16. Aloisi F, Pujol-Borrell R. Lymphoid neogenesis in chronic inflammatory diseases. Nat Rev Immunol 2006;6:205-217.

Received September 14, 2019 Accepted December 10, 2019 